\title{
The 6-min walk distance: change over time and value as a predictor of survival in severe COPD
}

\author{
V.M. Pinto-Plata*, C. Cote", H. Cabral", J. Taylor*, B.R. Celli*
}

The 6-min walk distance: change over time and value as a predictor of survival in severe COPD. V.M. Pinto-Plata, C. Cote, H. Cabral, J. Taylor, B.R. Celli. C) ERS Journals Ltd 2004

ABSTRACT: The 6-min walk distance (6MWD) is used to evaluate the functional capacity of patients with chronic obstructive pulmonary disease (COPD). The change in 6MWD over time and its correlation with changes in spirometry and survival are unclear.

Patients (n=198) with severe COPD and 41 age-matched controls were followed for $2 \mathrm{yrs}$, and anthropometrics, spirometry, 6MWD and comorbidities were measured.

The 6MWD decreased in the COPD group from $238 \pm 107 \mathrm{~m}$ to $218 \pm 112 \mathrm{~m}$ $\left(-26 \pm 37 \mathrm{~m} \cdot \mathrm{yr}^{-1}\right)$, and increased in the control group from $532 \pm 82 \mathrm{~m}$ to $549 \pm 86 \mathrm{~m}$ $\left(12 \pm 25 \mathrm{~m} \cdot \mathrm{yr}^{-1}\right)$. In both groups, there was a poor correlation with changes in forced expiratory volume in one second (FEV1). Nonsurvivors in the COPD group (42\%) had a more pronounced change in the 6MWD $\left(-40\right.$ versus $\left.-22 \mathrm{~m} \cdot \mathrm{yr}^{-1}\right)$ but a similar change in FEV1 (118 versus $\left.102 \mathrm{~mL} \cdot \mathrm{yr}^{-1}\right)$. The 6MWD independently predicted survival, after accounting for age, body mass index, FEV1 and comorbidities.

In severe chronic obstructive pulmonary disease, the 6-min walk distance predicts mortality better than other traditional markers of disease severity. Its measurement is useful in the comprehensive evaluation of patients with severe disease.

Eur Respir J 2004; 23: 28-33.
*Division of Pulmonary and Critical Care Medicine, St Elizabeth's Medical Center, Tufts University School of Medicine, "Department of Biostatistics Boston University School of Public Health, Boston, MA, and ${ }^{\#}$ Pulmonary-Critical Care Medicine Bay Pines VA Medical Center, Tampa, FL, USA.

Correspondence: B.R. Celli, St Elizabeth's Medical Center, 736 Cambridge Street, Boston, MA 02135, USA.

Fax: 16175627756

E-mail: bcelli@cchcs.org

Keywords: Chronic obstructive pulmonary disease

functional capacity

6-min walk distance

Received: March 272003

Accepted after revision: September 232003
Chronic obstructive pulmonary disease (COPD) ranks as one of the leading causes of death and disability in the world [1-3]. Management of patients with COPD includes education, preventive care, smoking cessation, pharmacological and oxygen therapy, and pulmonary rehabilitation [2, 4-6]. Traditionally, the severity of COPD is graded according to the degree of airflow limitation, expressed by the forced expiratory volume in one second (FEV1) of the forced vital capacity (FVC) manoeuvre. This simple test is a useful predictor of morbidity and mortality. In addition, the defining characteristics of FEV1 and its change over time in patients with COPD have been well studied [4, 7, 8]. In spite of these characteristics, the FEV1 incompletely describes other negative attributes of COPD. It is not a good predictor of dyspnoea, the most frequent clinical complaint of patients suffering from the disease, and in those patients with the most severe obstruction, it is also a poor predictor of survival, hospitalisation frequency and functional capacity $[4,9,10]$.

The 6-min walk distance (6MWD) is a test used to assess the functional status of patients with COPD. Introduced in 1976 as a 12-min walk test to measure exercise capacity for patients with chronic lung disease [11], over time it has proved to be reliable, objective, inexpensive and easy to apply regardless of the patient's age or educational level [12-16]. It has been shown to predict survival postpulmonary rehabilitation [9], and to predict postoperative morbidity and mortality after lung volume reduction surgery [17]. In addition, a threshold for noticeable differences in patients' subjective comparison ratings of their walking has been determined [18]. Owing to these advantages and its relative standardisation [19], the 6MWD test is increasingly used to complement the evaluation of patients with COPD.
In contrast to knowledge regarding the natural history of lung function decline over time, there is no longitudinal data about the 6MWD in patients with COPD. Reference equations have been proposed to calculate the distance walked by healthy adults, based on a single 6MWD test with no followup $[20,21]$. If the $6 \mathrm{MWD}$ represents a measurement that changes independently of FEV1, it perhaps could be used as a parameter to evaluate the clinical status of patients, particularly those with the most severe COPD, in whom FEV1 may not completely reflect functional and health status. The value of the 6MWD as a predictor of mortality has not been prospectively studied in a cohort of patients with severe disease without any other intervention (i.e. pulmonary rehabilitation). Finally, the value of the 6MWD as a predictor of mortality has not been compared prospectively with that of traditional markers of disease severity such as body mass index (BMI) or degree of comorbidity.

\section{Material and methods}

\section{Study subjects}

Patients with COPD, referred to the pulmonary departments at St Elizabeth's Medical Center and Bay Pines Veterans Administration Hospital, were prospectively enrolled. The protocol was approved by the institutional review board of both hospitals. Primary care physicians referred patients or pulmonologists to perform pulmonary function tests, assess their performance status and evaluate requirement for oxygen therapy during physical activity. Controls were healthy hospital employees or healthy volunteers recruited by 
a newspaper advertisement. Patients with COPD were included if they met the American Thoracic Society (ATS) criteria for the diagnosis of COPD (FEV1/FVC and FEV1 $<70 \%$ predicted) [4]. Patients were excluded if they have had an exacerbation of COPD the last 4 months, another unstable medical problem, or if they refused to sign a consent form.

\section{Study design}

Once selected, oxygen saturation value, use of oxygen and pulmonary function tests were recorded. All the patients performed the 6MWD after the pulmonary function was assessed, and nebulised albuterol $\left(2.5 \mathrm{mg} \cdot 3 \mathrm{~mL}^{-1}\right)$ was given (COPD patients). Patients were re-evaluated $\geqslant 1$ yr after the first evaluation (follow-up), but this evaluation was postponed for $\geqslant 1 \mathrm{yr}$ if the patient was involved in pulmonary rehabilitation or for 4 months if they had been admitted into the hospital. The follow-up time was recorded in months. For patients who died, date and cause of death were verified by reviewing the hospital or referring physician's medical records.

\section{The 6-min walk distance test}

Patients completed two 6MWD tests per evaluation of $\geqslant 30 \mathrm{~min}$ apart, following a modified protocol [14, 19]. The modifications included the use of a $36 \mathrm{~m}$ long corridor, encouragement of the patient, oxygen saturation monitoring and oxygen provision to the patients whose oxygen saturation decreased to $<85 \%$. The respiratory therapist carried the oxygen tank. The longest of the two walk distances was used in analysis. The same respiratory nurse on each site performed the evaluations during the time span of the study. For all the patients, the minimal time between two evaluations was $1 \mathrm{yr}$. This minimised the possible influence of pulmonary rehabilitation on the walked distance in the nine patients who enrolled in pulmonary rehabilitation.

\section{Physiological and anthropometric measurements}

Pulmonary function tests were performed following the ATS standards [22]. Weight and height were measured and the BMI was calculated. The degree of comorbidity was assessed using the validated Charlson Index [23].

The Charlson comorbidity index was designed to classify prognostic comorbidity in longitudinal studies. It has been used in several studies to stratify patients in order to control for the confounding influence of comorbid conditions on overall survival. It combines the risk from age and the risk from comorbid disease into a single variable, estimating the risk of death. The conditions have a specific weight. A higher Charlson comorbidity score indicates an increased severity of condition and a higher relative risk of death.

\section{Statistical analysis}

Descriptive data for continuous variables are presented as mean $\pm \mathrm{SD}$ and percentages are presented for categorical variables. T-tests were used to compare changes between the baseline and subsequent measurements for each group. Pearson's correlation was used to describe the association between continuous variables. A Chi-squared test was used to compare the difference in mortality according to the categorised distance walked. Formal survival analyses were performed adjusting for censoring via the Kaplan-Meier method to compare patients by categories of 6MWD $(<100$, 101-200, 201-300, and $>300 \mathrm{~m}$ ). In addition, Cox proportional hazards regression [24] was used to assess the potential independent effect of continuous 6MWD as a predictor of survival after accounting for age, BMI, FEV1 and comorbidity. p-values of $<0.05$ were deemed significant.

\section{Results}

A total of 198 patients with COPD and 41 age-matched controls were included in the study (table 1). Both groups had statistically different BMI, FEV1, 6MWD, and changes in FEV1 and 6MWD during the study period.

Of the 198 patients, $114(58 \%)$ were able to perform two different walking evaluations and concomitant pulmonary function tests, $\geqslant 1 \mathrm{yr}$ apart, and were alive at the end of the study (group 1). Forty-two patients $(21 \%)$ who completed two evaluations died during the study period (group 2) and 42 $(21 \%)$ died after completing only one evaluation (group 3; fig. 1). Eight patients were excluded from the study because they were involved in pulmonary rehabilitation $<1$ yr before the evaluation, and nine patients were included $1 \mathrm{yr}$ after rehabilitation (four, three and two patients in groups 1, 2 and 3 , respectively).

Table 2 shows the clinical characteristics of the COPD patients divided in the three groups. The patients were different in terms of age, BMI and spirometric values. The

Table 1.-Clinical characteristics in control and chronic obstructive pulmonary disease (COPD) group

Control group COPD group p-value

\begin{tabular}{lccc}
\hline Subjects n & 41 & 198 & \\
Male \% & 76 & 85 & NS \\
Age yrs & $67 \pm 5$ & $68 \pm 9$ & NS \\
BMI kg $\cdot \mathrm{m}^{-2}$ & $28.24 \pm 4.69$ & $24.86 \pm 5.74$ & 0.001 \\
FEV1 L & $2.54 \pm 0.63$ & $1.04 \pm 0.39$ & 0.001 \\
Change in FEV1 mL·yr ${ }^{-1}$ & $-37 \pm 228$ & $-106 \pm 173$ & 0.003 \\
First 6MWD m & $532 \pm 82$ & $238 \pm 107$ & 0.001 \\
Change in 6MWD m·yr ${ }^{-1}$ & $12 \pm 25$ & $-26 \pm 37$ & 0.001 \\
Follow-up period yrs & $2.0 \pm 0.7$ & $1.9 \pm 1.2$ & NS \\
\hline
\end{tabular}

BMI: body mass index; FEV1: forced expiratory volume in one second; 6MWD: 6-min walk distance. NS: nonsignificant.

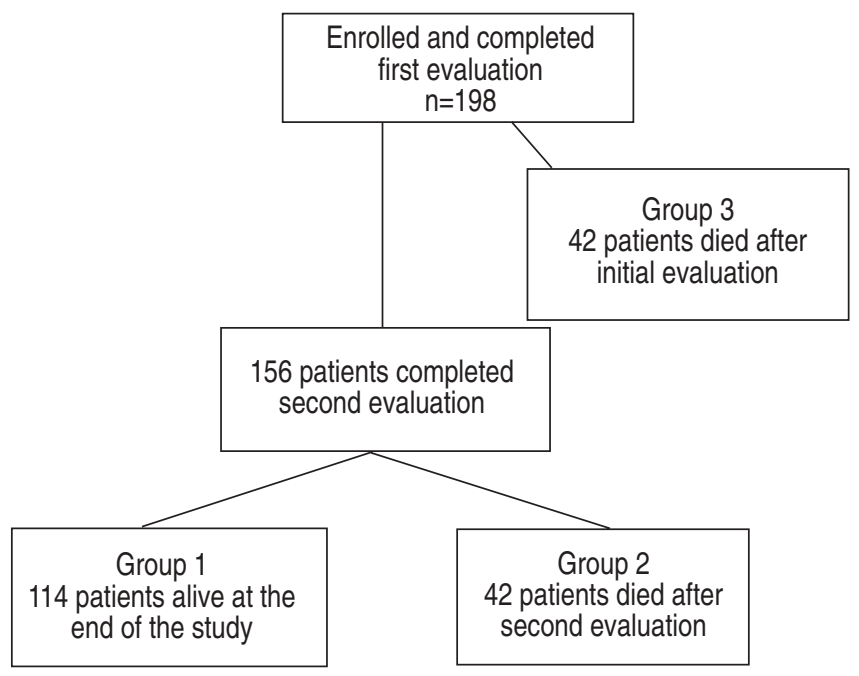

Fig. 1.- Flow diagram of patients enrolled in the study. 
Table 2.-Clinical, anthropometrics, pulmonary function test and 6-min walk distance (6MWD) in patients with chronic obstructive pulmonary disease

\begin{tabular}{|c|c|c|c|c|c|}
\hline & \multirow[t]{2}{*}{ Group 1} & \multicolumn{2}{|c|}{ Group 2} & \multicolumn{2}{|c|}{ Group 3} \\
\hline & & Values & p-value ${ }^{\#}$ & Values & p-value ${ }^{\#}$ \\
\hline Subjects $n$ & 114 & 42 & & 42 & \\
\hline $\mathrm{M} / \mathrm{F}$ & $91 / 23$ & $39 / 3$ & & $35 / 7$ & \\
\hline Age yrs & $66 \pm 9$ & $69 \pm 8$ & $<0.04$ & $71 \pm 7$ & $<0.003$ \\
\hline $\mathrm{BMI} \mathrm{kg} \cdot \mathrm{m}^{-2}$ & $25.95 \pm 5.91$ & $23.65 \pm 4.80$ & $<0.02$ & $23.49 \pm 5.98$ & $<0.02$ \\
\hline FEV1 L & $1.13 \pm 0.40$ & $0.94 \pm 0.32$ & $<0.006$ & $0.88 \pm 0.36$ & $<0.0007$ \\
\hline First 6MWD m & $275 \pm 98$ & $221 \pm 103$ & $<0.002$ & $155 \pm 80$ & $<0.0$ \\
\hline Follow-up period yrs & $2.0 \pm 1.3$ & $1.8 \pm 1.3$ & & $1.1 \pm 1.0$ & \\
\hline
\end{tabular}

Data are presented as mean \pm SD unless otherwise stated. Group 1: alive, two evaluations; Group 2: deceased, two evaluations; Group 3: deceased, one evaluation. M: male; F: female; BMI: body mass index; FEV1: forced expiratory volume in one second. ${ }^{\#}$ : compared with group 1; ${ }^{\uparrow}$ : time between first evaluation and death.

nonsurvivors (group 2 and 3) were older, had lower BMI and FEV1 values, and walked shorter distances. The duration of the follow-up period was similar between groups 1 and 2 .

The majority of the patients in the COPD group were male $(83 \%)$. There was no difference in age but females had sigificantly higher BMI values (26.80 versus $24.44 \mathrm{~kg} \cdot \mathrm{m}^{-2}$ ), FEV1 values $(40 \%$ versus $34 \%$ ), and a tendency to walk shorter distances during the 6MWD (245 versus $208 \mathrm{~m}$, $\mathrm{p}<0.07)$.

Figure 2 shows the difference in the 6MWD during the first and second evaluation of groups 1 and 2 . The distance walked by patients in group 1 (survivors) during the first evaluation was $275 \pm 98 \mathrm{~m}$ and it decreased to $236 \pm 111 \mathrm{~m}(\mathrm{p}<0.001)$ in the follow-up evaluation. This represents a mean decrease of $21 \pm 31 \mathrm{~m} \cdot \mathrm{yr}^{-1}$. In group 2 (dead after the second evaluation), the distance decreased from $221 \pm 103 \mathrm{~m}$ to $169 \pm 97 \mathrm{~m}(\mathrm{p}<0.001)$, a mean decrease of $40 \pm 47 \mathrm{~m} \cdot \mathrm{yr}^{-1}$. Similarly, there was a decrease in FEV1 (group 1) from 1.13 $\pm 0.40 \mathrm{~L}$ to $0.98 \pm 0.39 \mathrm{~L}(\mathrm{p}<0.001)$, a mean decrease of $102 \pm 172 \mathrm{~mL} \cdot \mathrm{yr}^{-1}$. In the second group, it decreased from $0.94 \pm 0.32 \mathrm{~L}$ to $0.77 \pm 0.28 \mathrm{~L}(\mathrm{p}<0.001)$, with a mean decrease of $118 \pm 130 \mathrm{~mL} \cdot \mathrm{yr}^{-1}$. The change in the distance walked per year is significantly higher for group 2 compared with group 1 (-40 versus $-21 \mathrm{~m}$, respectively; $\mathrm{p}<0.004)$. The change in FEV1, however, was not significantly different between both groups $\left(-118\right.$ versus $102 \mathrm{~mL} \cdot \mathrm{yr}^{-1}$, $\mathrm{p}<0.58$ ).

There was a good correlation between the first and second FEV1 $(r=0.89, p<0.01), 6 M W D(r=0.84, p<0.01)$ and BMI $(\mathrm{r}=0.90, \mathrm{p}<0.01)$ for the patients in groups 1 and 2 . Other correlations were weaker for the same groups including first FEV1 versus first 6MWD $(\mathrm{r}=0.44, \mathrm{p}<0.001)$, and second FEV1 versus second $6 \mathrm{MWD}(\mathrm{r}=0.56, \mathrm{p}<0.001)$. There was no significant correlation between the change in FEV1 per year versus change in 6MWD per year $(\mathrm{r}=0.09, \mathrm{p}<0.22)$, and change in BMI versus change in $6 \mathrm{MWD}(\mathrm{r}=0.05, \mathrm{p}=0.57)$.

Despite the difference in the distance walked by the group of survivors and nonsurvivors, there was a significant overlap of individual values in the 6MWD by these two groups, as shown in figure 2. However, a Chi-squared test analysis showed a significant statistical difference $(p<0.0001)$ between the distances walked, divided into $100 \mathrm{~m}$ categories, and the observed mortality (fig. 3)

To confirm this finding adjusting for censoring, survival analyses were performed via the Kaplan-Meier method to compare patients by categories of 6MWD (fig. 4). A log rank test showed that the categories had significantly different survival $(p<0.001)$, with longer times to death observed in categories of longer 6MWD.

The presence of comorbidities is displayed in table 3 . The combined comorbidity index by Charlson was used to control for the confounding influence of comorbid conditions on
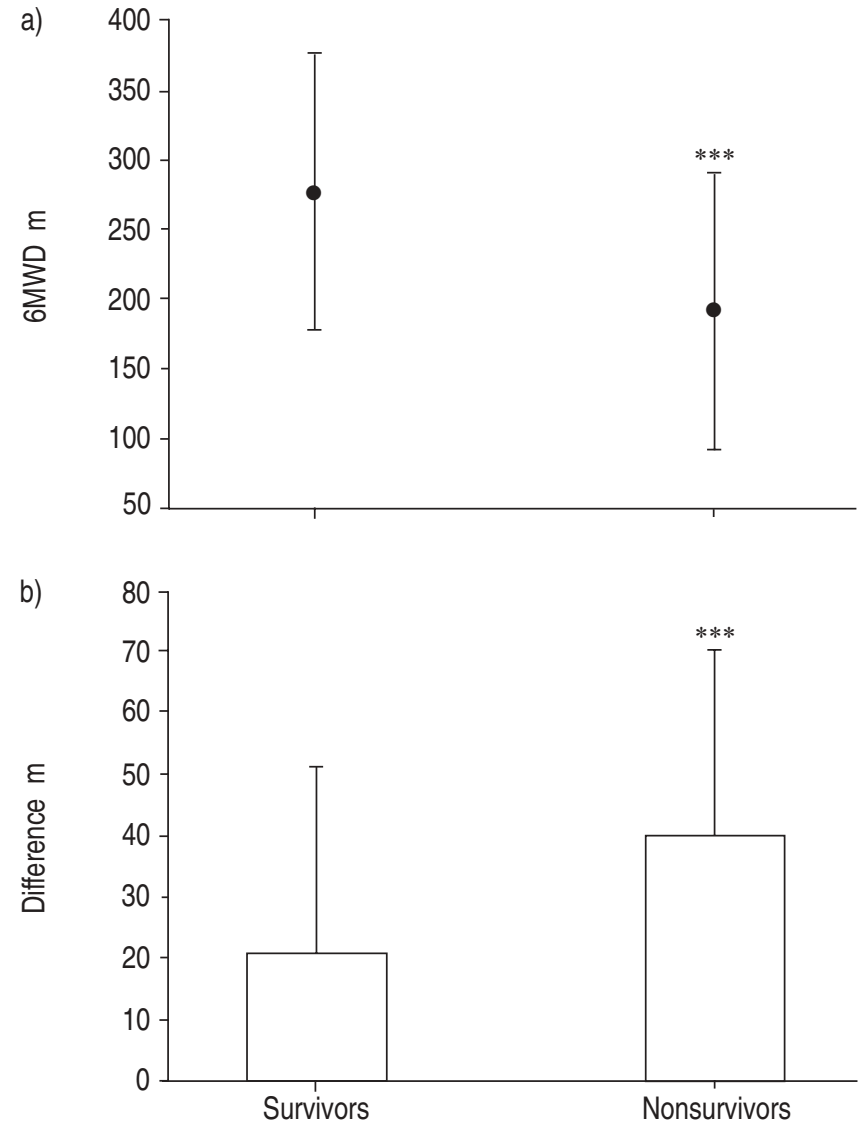

Fig. 2. - a) Patients who survived had a significantly higher mean 6min walking distance $(6 \mathrm{MWD})$ value $(275 \pm 98 \mathrm{~m})$ compared with patients who died $(188 \pm 98 \mathrm{~m})$. However, there is a significant overlap between the individual patients in both groups. b) Difference (mean \pm SD) between the first and second 6MWD evaluation in the group of survivors (group 1) and nonsurvivors (group 2). ***: $\mathrm{p}<0.001$.

overall survival. There was no significant difference in the number of comorbidities among the three groups adjusted by age $(\mathrm{p}=0.09)$.

The potential independent effect of continuous 6MWD as a predictor of survival was assessed in a Cox proportional hazards regression model accounting for age, BMI, FEV1 and comorbidities (table 4). It was found that 6MWD was a significant predictor of survival with a risk ratio of death of 0.82 per $50 \mathrm{~m}$ increase in $6 \mathrm{MWD}(95 \%$ confidence interval $0.72-0.94, \mathrm{p}<0.003)$. 


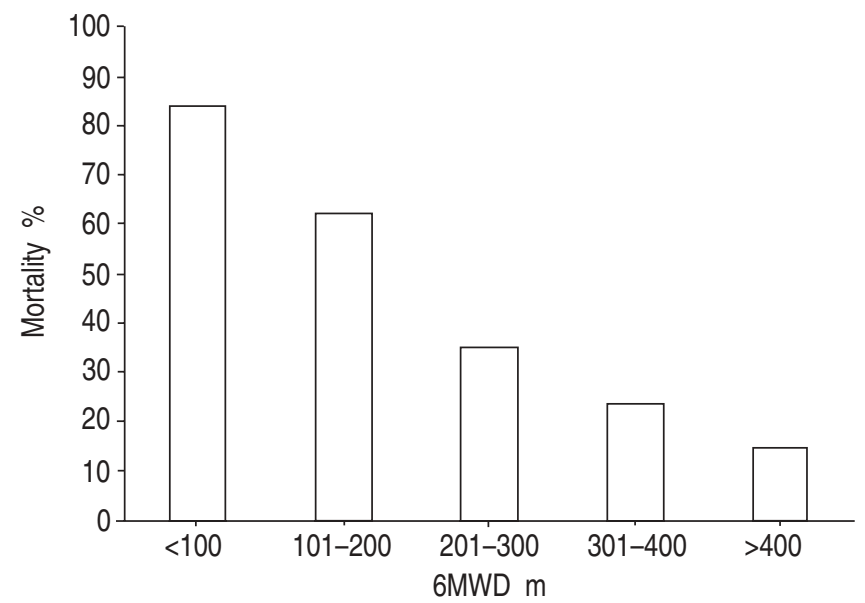

Fig. 3.-Mortality progressively decreases as the 6-min walking distance (6MWD) increases. For distances $<100 \mathrm{~m}, \mathrm{n}=19$; for $101-$ $200 \mathrm{~m}, \mathrm{n}=61$; for $201-300 \mathrm{~m}, \mathrm{n}=57$; for $301-400 \mathrm{~m}, \mathrm{n}=46$; and for $>400 \mathrm{~m}, \mathrm{n}=15$.

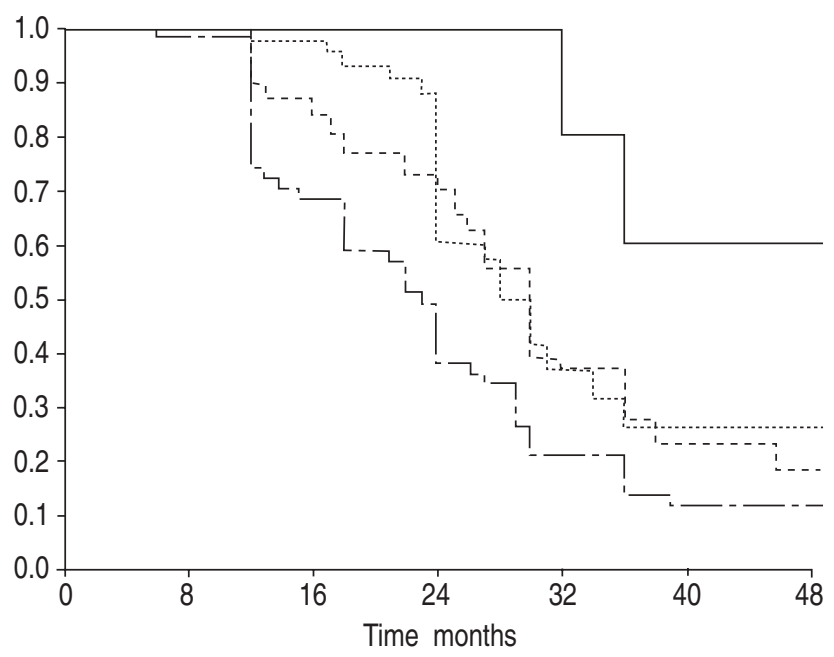

Fig. 4. - Kaplan-Meier curves comparing survival with four different walked distances. - : >301 m; - - -: 201-300 m; …..... 101-200 m; $-\cdot-\cdot<100 \mathrm{~m}$.

Table 3. - List of comorbidities in each group using Charlson Index

\begin{tabular}{lccc}
\hline Comorbidities \% & Group 1 & Group 2 & Group 3 \\
\hline Peripheral vascular disease & 7 & 7 & 10 \\
Cerebrovascular accident & 1 & 0 & 0 \\
Congestive heart failure & 10 & 17 & 7 \\
Coronary artery disease & 23 & 14 & 21 \\
Chronic renal failure & 5 & 0 & 0 \\
Myocardial infarction & 5 & 2 & 0 \\
Dementia & 3 & 2 & 0 \\
Connective tissue disease & 4 & 0 & 0 \\
Peptic ulcer disease & 6 & 2 & 0 \\
Diabetes mellitus & 16 & 7 & 7 \\
Liver disease & 2 & 0 & 0 \\
Malignancies & 17 & 29 & 12 \\
Severe liver disease & 0 & 0 & 0 \\
Total & 2.13 & 1.76 & 1.66 \\
Total (age-adjusted) & 4.29 & 4.14 & 4.19 \\
\hline
\end{tabular}

Table 4. - Cox proportional hazards model

\begin{tabular}{lcc}
\hline & HR $(95 \% \mathrm{CI})$ & p-value \\
\hline 6MWD m & $0.996(0.993-0.999)$ & 0.003 \\
Age yrs & $1.03(1.01-1.06)$ & 0.04 \\
FEV1 L & $0.80(0.40-1.60)$ & 0.53 \\
BMI kg m $^{-2}$ & $0.95(0.91-0.99)$ & 0.01 \\
Charlson Index & $0.84(0.68-1.03)$ & 0.10 \\
\hline
\end{tabular}

HR: hazard ratio; $\mathrm{CI}$ : confidence interval; 6MWD: 6-min walk distance; FEV1: forced expiratory volume in one second; BMI: body mass index; There were 84 deaths and 114 censored observations (58.8\%). Model p-value was $<0.0001$.

\section{Discussion}

This study has three major findings. First, it describes the change over time in 6MWD in patients with severe COPD. Secondly, it shows that independent of comorbid conditions the 6MWD is a better predictor of mortality than FEV1and BMI in this subset of patients. Thirdly, it shows that in patients with severe disease, the decline in 6MWD occurs independently of the change in FEV1.

This is the first controlled study that describes longitudinal changes in the 6MWD in patients with severe COPD. Most of the previous reports emphasise the reliability of the test, its validity, safety, reproducibility, correlation among 2-, 6- and 12MWD test [11-13], the effect of encouragement [14] and the value of the test, as a predictor of survival in different clinical conditions $[9,15,17,25,26]$. However, all these characteristics and correlations have been described in a single 6MWD evaluation without any follow-up measurements. In this study all but 35 patients $(23 \%)$ walked a shorter distance on the second evaluation. This implicates a deterioration in the patient's physiological status, which could be due to multiple factors. These include worsening of the pulmonary condition, deterioration of another organ system, physical deconditioning or systemic effects of COPD. It is impossible to determine the individual contribution of each of these factors in the observed change, but they must be important, as a lower 6MWD was associated with a higher mortality.

The authors believe that the 6MWD test should be considered in the evaluation of patients with severe COPD, and the decline in the distance walked that occurs over time should be followed closely for different reasons. First, the observed change in the 6MWD was independent of changes in the FEV1. Secondly, the rate of decline in the 6MWD per year was different between the group of survivors and nonsurvivors, but the decrease in FEV1 was not. Thirdly, there is an inverse relationship between the distance walked and mortality. Therefore, it seems that the FEV1 and 6MWD have an important and independent value as monitors of patients with COPD. The FEV1 is useful to classify patients at different levels of disease severity, and based on it, to predict mortality. However, when the disease becomes severe or very severe (i.e. FEV1 $<50 \%$ pred), the 6MWD test seems to be a better mortality predictor. The limited information provided by the spirometric value when used as the sole tool in the assessment of patients with severe COPD is supported by these results.

A weak correlation was found between the distance walked and the FEV1. This finding is consistent with that of MCGAVIN et al. [11] who initially reported a poor correlation between the distance walked and FEV1 ( $r=0.28)$. Subsequent work from the same authors described a better correlation $(r=0.44)$ between both values, but they concluded that the scatter of the results made exercise performance difficult to predict from respiratory function tests [12]. In this study, a poor correlation was also found between the 6MWD and the FEV1 during the second walking test evaluation and this 
correlation was even weaker when the rate of change in both tests was compared. There has been no report, prospective or retrospective, of this poor relationship over time in a group of COPD patients. It seems reasonable to conclude that when patients reach a severe degree of airflow limitation, the correlation between FEV1 and 6MWD is weak at best. The best explanation for this observation is that the distance walked depends not only on respiratory function, but also on the cardiopulmonary, nutritional and peripheral muscle status of the individual $[15-17,25,26]$. It also suggests that both tests measure different aspects of the patient's disease state. The FEV1 most likely expresses the respiratory system involvement, whereas the 6MWD may represent the systemic effects associated with the disease.

These results are supported by several outcome studies in different patient populations, in which the value of timed walking distance measurements predicting morbidity and mortality has been tested. One previous publication described an association between the distance walked and increased mortality and morbidity in patients with left ventricular dysfunction [15]. The group of patients who walked less $(<300 \mathrm{~m})$ had a significantly greater chance of dying or being hospitalised compared with the group with better performance. Similar results were obtained by CAHALIN et al. [26] in patients with heart failure, in whom they found an increased likelihood of death or pretransplant hospital admission for continuous inotropic or mechanical support within 6 months, if patients walked $<300 \mathrm{~m}$ over $6 \mathrm{~min}$. Мічамото et al. [25] found the 6MWD test to be the only variable independently related to mortality in primary pulmonary hypertension. In this study, patients walking $<332 \mathrm{~m}$ had a significantly lower survival rate than those walking farther. In a retrospective analysis, GERARDI et al. [9] studied 158 patients after pulmonary rehabilitation ( $40 \pm 17$ months), and observed that the 12MWD test was the most significant variable related to prognosis. Indeed, the 12MWD was better than FEV1, arterial blood gases, BMI, age, albumin and common comorbid conditions in predicting mortality. A more recent study by BowEN et al. [27] showed that postrehabilitation functional activities score (measured by a self-completed questionnaire), being married and a longer 6MWD were associated with increased survival. In a study of 41 patients with COPD undergoing lung volume reduction surgery, the inability to walk $\geqslant 200 \mathrm{~m}$ over $6 \mathrm{~min}$ was a good predictor of postoperative complications and overall mortality [17]. Taken together these reports strongly support the value of a walking distance test in the global assessment of patients with chronic debilitating diseases.

The present study has some limitations. First, $86 \%$ of the patients had severe COPD (FEV $1<50 \%$ pred) with elevated mortality $(21 \%$ per year), limiting the conclusions to this subset of patients. The high mortality was attributed to the fact that both pulmonary divisions constitute referral centres of COPD patients treated by internal medicine practitioners and pulmonary disease specialists, who usually refer the most ill and physically limited patients for evaluation. Although the authors did not select the population, they are "selected" by their referral physician. Nevertheless, this is the group of patients with the highest mortality and probably the one in which the 6MWD may better predict this outcome. Secondly, only two evaluations were performed during the study period and the time span between them was relatively short $(2 \mathrm{yrs})$ to better estimate the rate of decline in FEV1. However, other groups have also used two measurements to estimate the rate of decline in FEV1 [28], and despite the short interval, the authors were able to show a change of $37 \mathrm{~mL} \cdot \mathrm{yr}^{-1}$ in $\mathrm{FEV} 1$ in the control group, a value similar to those reported in the literature [4]. The COPD group had a higher rate of decline $\left(106 \pm 173 \mathrm{~mL} \cdot \mathrm{yr}^{-1}\right)$ and this may represent a subset of patients with severe disease and "rapid decline" in lung function. Thirdly, the narrow range in spirometry values may have prevented the authors from finding a better relationship between the change in FEV1 and decline in 6MWD. Nevertheless, a nonsignificant correlation was also found in the control population $(r=0.29 \mathrm{p}<0.06)$, thereby supporting the findings. Fourth, there was an overlap in the individual values of 6MWD between survivors and nonsurvivors (fig. 2). Although the 6MWD did not provide perfect discrimination in predicting death, as a group, the individuals who died during the study period walked shorter distances, on average, particularly those who walked $<200 \mathrm{~m}$ (figs 3 and 4). Also, the probability of dying increased by $18 \%$ for every reduction of $50 \mathrm{~m}$ in the distance walked. Fifth, there was a disparity in the sex distribution, with more females in group 1 (alive with two evaluations). From previous reports [20, 21], it is known that the 6MWD is shorter in females compared with males, as it was in this case $(43 \mathrm{~m})$. Therefore, the presence of a larger number of females in group 1 makes the difference between survivors and nonsurvivors smaller than it could have been if the sexes were equally represented in both groups. Sixth, a few patients $(n=9)$ underwent pulmonary rehabilitation, which usually increases the 6MWD and may alter the results. However, the number of patients who were included in the study after pulmonary rehabilitation were similar in each group, they were studied $\geqslant 1$ yr postrehabilitation to minimise the potential benefit of it [29, 30], and there was no difference in the statistical analysis whether they were included or not.

In summary, this study shows that the distance walked during a 6MWD test by patients with severe COPD progressively declines over time. This decline occurs independently from the change in lung function. In spite of significant overlap in individual values, a shorter walked distance was confirmed to be associated with a higher mortality in COPD patients. The authors estimated the risk of dying by changes in the 6MWD and demonstrated that the 6MWD is a better predictor of mortality than FEV1, BMI or associated comorbidities.

The authors believe that a 6-min walk distance test adds important independent information to the routine evaluation of patients with severe chronic obstructive pulmonary disease and should be considered in the evaluation of these patients.

\section{References}

1. Feinlieb M, Rosemberg HM, Collins JG, Delozier JE, Pokras R, Chevarley FM. Trends in COPD morbidity and mortality in the United States. Am Rev Respir Dis 1989; 140: Suppl. 1, 9-18.

2. Siafakas NM, Vermeire P, Pride B, et al. Optimal assessment and management of chronic obstructive pulmonary disease (COPD). Eur Respir J 1995; 8: 1398-1420.

3. Anthonisen NR, Wright EC, Hodgkin JE. Prognosis in chronic obstructive pulmonary disease. Am Rev Respir Dis 1986; 133: 14-20.

4. Standards for the diagnosis and care of patients with chronic obstructive pulmonary disease. American Thoracic Society. Am Rev Respir Crit Care Med 1995; 152: Suppl. 2, S77-S120.

5. Celli BR. Is pulmonary rehabilitation an effective treatment for chronic obstructive pulmonary disease? Yes. Am J Respir Crit Care Med 1997; 155: 781-783.

6. Lacasse Y, Wong E, Guyatt GH, King D, Cook DJ, Goldstein RS. Meta-analysis of respiratory rehabilitation in chronic obstructive pulmonary disease. Lancet 1996; 348: $1115-1119$.

7. Fletcher CM, Peto R, Tinker C, Speizer FE. The Natural History of Chronic Obstructive Lung Disease in Working 
Men in London. New York, Oxford University Press, 1976.

8. Burrows B, Knudson RJ, Camilli AE, Lyle SK, Lebowitz MD. The "horse racing effect" and predicting decline in forced expiratory volume in one second from screening spirometry. Am Rev Respir Dis 1987; 135: 788-793.

9. Gerardi DA, Lovett L, Benoit-Connors ML, Reardon JZ, ZuWallack RL. Variables related to increased mortality following outpatient pulmonary rehabilitation. Eur Respir $J$ 1996; 9: 431-435.

10. Mahler DA, Weinberg DH, Wells CK, Feinstein AR. The measurement of dyspnea: contents, interobserver agreement, and physiologic correlates of two new clinical indexes. Chest 1984; 85: 751-758.

11. McGavin CR, Gupta SP, McHardy GJR. Twelve-minute walking test for assessing disability in chronic bronchitis. BMJ 1976; 1: 822-823.

12. McGavin CR, Artvinli M, Naoe H, McHardy GJR. Dyspnoea, disability, and distance walked: comparison of estimates of exercise performance in respiratory disease. BMJ 1978; 2: 241-243.

13. Butland RJA, Pang J, Gross ER, Woodcock AA, Geddes DM. Two, six, and 12-minute walking tests in respiratory disease. BMJ 1982; 284: 1607-1608.

14. Guyatt GH, Pugsley SO, Sullivan MJ, et al. Effect of encouragement on walking test performance. Thorax 1984; 39: 818-822.

15. Bittner V, Weiner DH, Yusuf S, et al. Prediction of mortality and morbidity with a 6-minute walk test in patients with left ventricular dysfunction. JAMA 1993; 270: 1702-1707.

16. Guyatt GH, Sullivan MJ, Thompson PJ, et al. The six-minute walk: a new measure of exercise capacity in patients with chronic heart failure. Can Med Assoc J 1985; 132: 919-923.

17. Szekely LA, Oelberg DA, Wright C, et al. Preoperative predictors of operative morbidity and mortality in COPD patients undergoing bilateral lung volume reduction surgery. Chest 1997; 111: 550-558.

18. Redelmeier DA, Bayoumi AM, Goldstein RS, Guyatt GH. Interpreting small differences in functional status: The six minute walk test in chronic lung disease patients. Am J Respir Crit Care Med 1997; 155: 1278-1282.
19. American Thoracic Society Statement. Guidelines for the six-minute walk test. Am J Respir Crit Care Med 2002; 166: 111-117.

20. Enright PL, Sherrill DL. Reference equations for the sixminute walk in healthy adults. Am J Respir Crit Care Med 1998; 158: 1384-1387.

21. Troosters T, Gosselink R, Decramer M. Six minute walking distance in healthy elderly subjects. Eur Respir $J$ 1999; 14: 270-274

22. American Thoracic Society. Standardization of spirometry: 1994 update. Am J Respir Crit Care Med 1994; 152: 11071136.

23. Charlson M, Szatrowski TP, Peterson J, Gold J. Validation of a combined comorbidity index. J Clin Epidemiol 1994; 47: $1245-1251$.

24. Cox DR. Regression models and life table (with discussion). J R Statist Soc 1972; B74: 187-220.

25. Miyamoto S, Nagaya N, Satoh T, et al. Clinical correlates and prognostic significance of six-minute walk test in patients with primary pulmonary hypertension. Comparison with cardiopulmonary exercise testing. Am J Respir Crit Care Med 2000; 161: 487-492.

26. Cahalin LP, Mathier MA, Semigran MJ, Dec GW, DiSalvo TG. The six-minute walk test predicts peaks oxygen uptake and survival in patients with advanced heart failure. Chest 1996; 110: 325-332.

27. Bowen JB, Votto JJ, Thrall RS, et al. Functional status and survival following pulmonary rehabilitation. Chest 2000; 118: 697-703.

28. Prescott E, Almdal T, Mikkelsen KL, Tofteng CL, Vestbo J, Lange P. Prognostic value of weight change in chronic obstructive pulmonary disease: results form the Copenhagen City Heart Study. Eur Respir J 2002; 20: 539-544.

29. Foglio K, Bianchi L, Ambrosino N. Is it really useful to repeat outpatient pulmonary rehabilitation programs in patients with chronic airway obstruction? A 2-year controlled study. Chest 2001; 119: 1696-1704.

30. Ries AL, Kaplan RM, Limberg TM, Prewitt LM. Effects of pulmonary rehabilitation on physiologic and psychosocial outcomes in patients with chronic obstructive pulmonary disease. Ann Intern Med 1995; 122: 823-832. 